\title{
An Overview of the Consequences of Distal Coronary Microembolization on Left Ventricular Function, Perfusion and Viability
}

\section{Maythem Saeed}

Department of Radiology and Biomedical Imaging, University of California, San Francisco, USA.

Email: MSaeed@ucsf.edu

Received December $8^{\text {th }}, 2010$; revised January $5^{\text {th }}, 2011$; accepted December $13^{\text {th }}, 2011$.

\begin{abstract}
Annually, an estimated 1,285,000 in-patient angioplasty procedures, 1,471,000 inpatient diagnostic cardiac catheterizations and 68,000 inpatient defibrillator implantations are performed. The direct and indirect cost of cardiovascular diseases for 2007 is approximately $\$ 431.8$ billion. The occurrence of plaque rupture with subsequent microemboli of atherosclerotic and thrombolytic debris into small coronary vessels has been confirmed. Microinfarction results from microemboli that are shed following coronary interventions. The aims of this review are to: 1) detect heterogeneous microinfarction using viability imaging, 2) characterize the consequences of distal coronary microembolization on left ventricle function and perfusion and 3) illustrate the progress of non-invasive imaging modalities in assessing distal coronary microembolization.
\end{abstract}

Keywords: Distal Coronary Microemblolization, Microinfarct, Left Ventricular Function, Cardiac Imaging

\section{Introduction}

Ischemic heart disease is the leading cause of death with an estimated 60 million cases each year and cost the healthcare system approximately $\$ 186$ billion. Clinical studies have shown that $42 \%$ of patients experience major cardiac events such as heart failure and sudden death after coronary intervention [1-6]. Microemboli, liberated during percutaneous coronary intervention (PCI), have been a well-recognized phenomenon in daily clinical practice. This phenomenon is not limited to PCI but includes a wide range of diseases, including valvular disease, prosthetic valve, endocarditis, cardiomyopathy, mural thrombus, arrhythmias and during heart-lungbypass in patients with congenital heart disease [7-13]. This pathology is also seen in patients with hypertension, diabetes [14], systemic lupus erythematosus [15] and sickle cell disease [16]. Clinical manifestations that could plausibly be associated with microinfarction include unstable anginal episodes that do not meet diagnostic criteria for acute homogeneous myocardial infarction and non-Q wave infarcts. Microinfarction may be subclinical in some patients but the cumulative effect of repetitive microinfarction could eventually result in evident deterioration of cardiac structure and function.
Given the vast patient population who experience embolic events, surprisingly little is known of the relationship between microinfarction, left ventricular (LV) function and arrhythmia. The American College of Cardiology and the European Society of Cardiology recently recognized the detrimental consequences of clinical coronary microemboli in their 2007 guidelines [17]. High incidences (30-50\%) of defects on myocardial perfusion scintigraphy have been detected after PCI with optimally implanted stents [18-21] and these events continued during follow-up [22-26]. Investigators found that the size and number of emboli dislodged from ruptured plaque is likely a key event in formation of microinfarction [27]. Several studies have identified distal coronary microemboli as the underlying etiology of LV dysfunction [14,17,28-30] and sudden death [29,31,32]. Coronary microemboli have also been recognized as a major source of arrhythmia, which may result in sudden death $[33,34]$. Currently, there is intensive work on providing reliable non-invasive diagnostic techniques that can be used to visualize microinfarction caused by distal coronary microemboli and assess the efficacy of new therapies and devices designed to treat or prevent microembolization. Such techniques should have the ability to 
quantify the effects of distal coronary microemboli on left ventricular function, perfusion and viability.

The aims of this review are to: 1) detect heterogeneous microinfarction using viability imaging, 2) characterize the consequences of distal coronary microembolization on left ventricle function and perfusion and 3) illustrate the progress of non-invasive imaging modalities in assessing distal coronary microembolization.

\section{Distal Coronary Microembolization}

Distal coronary microemboli and microinfarction has been identified at autopsy in patients with acute coronary syndromes who died of sudden cardiac death [35-42]. Okamura et al used an intracoronary Doppler guide wire to visualize and count microemboli during PCI in patients. The investigators found that the size of microemboli ranges between 47.16 to $2503.48 \mu \mathrm{m}$ [43]. Other investigators found that the size of microemboli in patients after sudden cardiac death due to coronary intervention averaged $250 \mu \mathrm{m}$ [44]. It was also found that size and volume of microemboli has a different impact on myocardial perfusion [45].

There have been relatively few studies, however, aimed specifically at assessing microinfarction, perfusion and function after PCI. Angelini et al indicated, "Little attention has thus far been given to the detection and prevention of microembolization [46]." Heusch et al. [47] reported that "Quantitative information on microinfarction is missing: the size and number of microemboli and associated microinfarction in a given heart or perfusion territory have not been reported so far." A recent study relates the volume of microemboli to myocardial damage [28]. In our studies we defined microinfarction on cardiac magnetic resonance (CMR)/multi-detector computed tomography (MDCT)/histochemical stain as a bright, small, unstained and necrotic lesion $\left(1-7 \mathrm{~mm}^{2}\right)$ within the area at risk. Invasive studies in animal models have shown LV dysfunction after delivery of embolic materials into coronary arteries [17,27,34,47-51]. The discrepancy between the damage and disproportional LV contractile dysfunction has been demonstrated [52]. Dörge et al. [53] found, $8 \mathrm{hrs}$ after delivery of $42 \mathrm{um}$ microspheres into the left circumflex coronary artery in swine model, that there was significant decrease in systolic wall thickening and an increase in LV end-diastolic pressure. The observed decrease in LV function was disproportionate to the extent of the myocardial damage. LV dysfunction has been attributed to the release of tumor necrosis factor (TNF)- $\alpha$ [33]. The effects of distal coronary microemboli have been investigated extensively using highly invasive methods and after administration of substantially higher load than seen clinically $[17,34,47$ -
50].

\subsection{Characterization of Distal Coronary Microembolization}

\subsubsection{Microscopic Investigations}

The most common form of distal coronary microemboli is atherosclerotic plaque. Atherosclerotic plaque is shed downstream into the microvasculature of the myocardium causing microinfarction. The earliest evidence of microembolization and microinfarction came from autopsy of patients who have died of sudden cardiac death $[29,31,32]$. These studies found that platelet microembolization can be one of the causes of acute coronary syndrome in patients. Post-mortem study of patients who died from sudden cardiac death revealed that microemboli are more common in vessels with plaque erosion than plaque rupture [54]. Microembolization is associated with invasion of polymorphonuclear leukocytes, monocytes and macrophages as inflammatory response $[29,32,53,55,56]$. Histopathology confirmed the presence of single and multiple microemboli in various diameter blood vessels which are surrounded by various extents of microinfarction. Embolized microvasculature showed endothelial sloughing and fibrin as contributors of microvascular obstruction, these changes were associated with edema and inflammatory cells out of the microvessels [55-59].

\subsubsection{Non-Invasive Imaging}

Microinfarct imaging is a challenge because of the low spatial resolution of conventional diagnostic scanners and motion artifacts. Cardiac magnetic resonance (CMR) and multi-detector computed tomography (MDCT) techniques are associated with unique imaging properties that define the achievable spatial and temporal resolutions and exhibit variable sensitivity and specificity to cardiac pathologies [60-67]. Multiple factors must also be considered when determining the most appropriate modality for a specific application, such as cost, availability in health care centers, patient tolerance, and contraindications.

CMR and MDCT imaging are noninvasive techniques that offers image contrast and tissue characterization. Today, they are accepted methods to quantify extent and severity of structural changes and in few cases to monitor response of therapies. CMR imaging has been used extensively to assess these parameters in clinical studies on large myocardial infarct and there has also been a few clinical studies describing these parameters following microembolization [28,30,55,56,68-71]. Cine MR imaging showed regional dysfunction in the embolized subregion compared to remote myocardium. These regional 
changes led to increase in LV volumes and decease in ejection fraction and cardiac output in the acute [72], but not chronic phase [59].

The advantages of CMR imaging are its potential to provide near simultaneous information on cardiac anatomy, function, perfusion and viability. CMR imaging has proven to be an extremely sensitive method for detecting microinfarction (as low as $2 \mathrm{~g}$ ) $[68,73,74]$. This technology has inherent strengths over the other clinically approved modalities that include: 1) the absence of radiation exposure, which is a strong motivation to further work on implementing CMR imaging after PCI; 2) the lack of administration of nephrotoxic iodinated contrast media; 3) CMR imaging is the method of choice for assessment of LV function and myocardial viability; 4) signal intensity differences of nearly 2-5 fold were identified between viable and non-viable myocardium; 5) serial assessments; 6) CMR imaging has the potential to measure 3D strain at rest and dobutamine stress; and 7) acquisition of images in any plane negates the need for post imaging reconstruction of images. Recent clinical studies showed a link between MR visualization of microinfarction and impaired myocardial perfusion $[68,75]$. Selvanayagam et al examined myocardial perfusion and necrosis serially after percutaneous coronary intervention with a validated, quantitative MR technique [30] and found that myocardial perfusion is reduced in segments with irreversible injury after PCI. CMR applications have been hampered by several technical issues, namely motion, magnetic field inhomogeneity, magnetization transfer saturation and sequence parameters.

More recently MDCT has been introduced to quantify viability and perfusion in large myocardial infarction [76-80] as well as acute and chronic microinfarction $[59,72]$. Viability MDCT imaging demonstrated the heterogeneous pattern of microinfarction, which is totally different from wave-front homogeneous large infarct, described by Jennings et al. [81]. Cine MDCT imaging demonstrates the decline in ejection fraction and increase in volumes as well as the perfusion deficit after bolus contrast injuction in micrembolized hearts [59,72].

The potential advantages of using MDCT include: 1) MDCT angiography is the method of choice for direct visualization of the coronary arteries, coronary calcium and atherosclerosis in its earliest stages; 2) the presence of LV assist devices do not preclude the performance of MDCT imaging; 3) the relatively fast acquisition time (7-10min) compared with cardiac MRI (45min), leads to cost and time savings; 4) scanning of claustrophobic or uncooperative patients; 5) less technical and personnel requirements for MDCT studies; 6) life-support and physiologic-monitoring equipments can be placed close to $\mathrm{CT}$ scanner and 7) CT contrast media provide linear relationship between attenuation and concentration on first pass perfusion MDCT [82]. In current practice, however, some of the inherent challenges for using MDCT imaging in ischemic heart disease include: i) exposure to radiation precludes serial assessment; ii) limited to stress-test (contractile reserve); iii) poor detection of edema in acute phase; and iv) extensive image post processing. It should be noted that other technologies, such as PET and SPECT imaging have low spatial resolution; therefore they are limited in visualizing microinfarction.

\section{Consequences of Microembolization}

Experimental studies have shown greater LV dysfunction in the microembolized territory than would be expected from the final extent of microinfarction $[33,56]$. The most likely explanation for the severe contractile dysfunction is rather the inflammatory reaction to microembolization and microinfarction. Heusch and co-workers have shown that the reasons for the contractile dysfunction are the release of tumour necrosis factor (TNF) $\alpha$ [83] and a myofibrillar oxidation [84]. Accordingly, investigators used non-specific anti-inflammatory glucocorticoid methylprednisolone [51], specific TNF- $\alpha$ antibodies [33], and the non-specific anti-oxidants ascorbic acid [84] for preventing the deleterious effects of coronary microembolization on LV dysfunction. These therapies showed some beneficial effects. Another study showed that TNF- $\alpha$ has an active role in protecting the myocardium from the formation of microinfarction after microembolization [83] and blocking TNF- $\alpha$ cause an increase in the extent of microinfarction [85]. Microinfarction, caused by the large volume of dislodged microemboli, can be detected at 24 hours by the release of biochemical markers of myocardial injury; such as creatine kinase and troponin $[17,86]$.

Clinical studies also identified coronary microemboli as a potential cause of left ventricular dysfunction in the absence of an atherosclerotic obstruction of an epicardial coronary artery [29,34]. Data confirmed that microinfarction activates arrhythmogenesis [34] and causes sudden death in patients [54]. Selvanayagam et al [87] found in 152 patients that even small amounts of procedure-related myocardial injury are associated with poor clinical outcome. Investigators found that $2-5 \%$ of LV microinfarction causes disproportional LV dysfunction [88]. Based on the results found in experimental animals $[59,72]$, we documented that the mortality rate is dependent on the volume of microemboli. A volume of 16 $\mathrm{mm}^{3}$ of $40-120 \mu \mathrm{m}$ microemboli caused no death in the first 72 hours after microembolization, whereas a volume 
of $66 \mathrm{~mm}^{3}$ of the same sizes of microemboli caused $25 \%$ mortality within the first 24 hours.

Microemboli may be one of the causes of mismatch between blood flow in the epicardial coronary arteries and LV function; a phenomenon which has been clinically observed after PCI $[89,90]$. The incidence of microembolization from coronary plaques vary from $30 \%$ [32], 54\% [54] to $81 \%$ [44]. The highest incidence was seen in patients who had recent PCI or thrombolysis [44]. In patients who underwent PCI, Selvanayagam et al. found a new area of infarct in $28 \%$ of patients after the procedure on contrast enhanced CMR imaging [69]. However, in half of the patients the new infarct after coronary intervention was interpreted to be caused by occluded side-branches, resulting in a $12 \%$ incidence of microinfarction possibly caused by microembolization [28].

The occurrence of plaque rupture with subsequent microemboli of atherosclerotic and thrombolytic debris into small coronary vessels has been confirmed [32,91] and that emboli sizes differ widely $[92,93]$. The direct and indirect clinical evidence for microemboli during PCI comes from distal protection devices [94-96] and elevation of creatine-kinase [97], respectively. The elevation of cardiac injury enzymes occurs in $10-40 \%$ of patients after PCI [34,46,68,98]. A follow-up study [53] in patients who underwent coronary angioplasty or coronary atherectomy found that the relative risk of cardiac death is increased 2.2-fold in patients whose creatine-kinase levels were elevated $>2$ times the upper normal range compared with patients whose creatine-kinase were not elevated. Such observations have been confirmed by subsequent studies $[27,48,49,53]$.

Recent clinical studies showed the perfusion deficit in embolized myocardium $[55,59]$ and increase in epicardial coronary flow [53]. The increase in epicardial flow at rest has been linked to release of adenosine from myocardium not affected by the microemboli $[27,99]$. However, at stress a decreased coronary reserve is seen because the microvascular obstruction in the microembolized territory. The perfusion deficit in the microembolized territory is ameliorated with time and at one week the decrease has partially recovered [55,59].

Other investigators suggested that distal coronary microemboli might be one of the causes to inadequate flow in the epicardial vessels despite apparently successful revascularization in patients treated with PCI for ST-elevation myocardial infarctions [100]. CMR imaging, using first-pass perfusion, high-resolution viability and cine, could provide further insights to the pathophysiology behind this pathology [101].
Our recent studies (unpublished data) demonstrated that microinfarction is surrounded by edematous periinfarction zone (viable and nonviable), which might be the cause of arrhythmia [102]. The arrhythmogenic effects of the peri-infarction zone have been confirmed in recent clinical studies [103-105]. The proposed pathophysiological explanation is that the tissue heterogeneity with re-entrant ventricular tachycardia is promoted in patchy infarcts with interwoven bundles of myocytes $[103,106]$.

\section{Cardiac Protection}

Catheter-based coronary intervention has been introduced as an alternative to conventional surgery for patients with high risk due to comorbidities and age. Catheter-based coronary intervention is performed while the heart is beating and coronary flow is not interrupted. Coronary plaques and debris are disrupted during the passage of the guide wire, positioning of the balloon and stent implantations. When oversized stent or higher pressures are used, strain on the plaque would increase, resulting in microemboli being sloughed into the lumen of the artery through stent struts, thereby increasing the risk for distal microinfarction. Based on the histological analysis of retrieved debris, the Enhanced Myocardial Efficacy and Recovery by Aspiration of Liberated Debris (EMERALD) trial, showed visible debris in $78 \%$ of patients [107]. Thus, the use of distal protection devices in capturing emboli seems to be very attractive.

Several protection devices have been proposed to prevent distal emboli, including proximal or distal protection devices and thrombectomy catheters $[94,108,109]$. Distal protection devices are non-occlusive devices that are positioned distal to the target lesion to filter emboli sloughed into the lumen of the artery during PCI. The results of randomized trials on adjunctive mechanical devices to prevent distal emboli, however, are conflicting. Initial results in a non-randomized trial have been promising [96]. Distal protection devices, such as the FilterWire EZ System, have been shown to reduce the incidence of microinfarction and adverse cardiac events in patients undergoing saphenous vein graft interventions [110]. Patel et al. revealed that distal protection devices reduce microcirculation damage and improve LV function in patients [110]. In a recent study, it was found that thrombus aspiration during PCI reduces the number of distal coronary microemboli and hence cellular damage [111]. Others suggested that the impact of these devices on myocardial perfusion and clinical outcome in patients remains limited [112]. There have been considerable advances in developing devices and therapies for minimizing the effects of microemboli during coronary inter- 
vention and improving microvascular function $[43,46,95$, $113,114]$.

Other therapeutic approaches include the use of glycoprotein IIb/IIIa inhibitors. Previous studies have provided evidence of the beneficial effect of glycoprotein IIb/IIIa receptor inhibitors on the microvasculature $[115,116]$. The glycoprotein IIb/IIIa inhibitor, tirofiban, is a synthetic, non-peptide inhibitor acting at glycoprotein (GP) IIb/IIIa receptors in platelets. Specific platelet glycoprotein IIb/IIIa receptor inhibitors with powerful antiplatelet aggregation properties have been found to attenuate no-reflow [116,117]. The exact cause of this beneficial effect is, however, unclear. Yang et al found that tirofiban is very effective in improving perfusion of infarcted myocardium [118]. These findings support the concept that endothelial protection, apart from platelet inhibition, contributes to the efficacy of tirofiban on cardiac perfusion.

In conclusion, early detection, characterization and treatment of microinfarction reduce morbidity and mortality. The ability to non-invesively monitor the effects of distal coronary microemboli could have profound implications on patient management after coronary intervention or in other diseases associated with distal coronary microembolization. Non-invesive imaging may be useful in assessing the effectiveness of new devices and therapies designed to capture microemboli and reduce the microinfarction effects on left ventricular function, perfusion and viability, respectively.

\section{REFERENCES}

[1] C. A. Beltrami, N. Finato, M. Rocco, G. A. Feruglio, C. Puricelli, E. Cigola, F. Quaini, E. H. Sonnenblick, G. Olivetti and P. Anversa, "Structural Basis of End-Stage Failure in Ischemic Cardiomyopathy in Humans," Circulation, Vol. 89, No. 1, 1994, pp. 151-163.

[2] C. Klein, S. G. Nekolla, F. M. Bengel, M. Momose, A. Sammer, F. Haas, B. Schnackenburg, W. Delius, H. Mudra, et al., "Assessment of Myocardial Viability with Contrast-Enhanced Magnetic Resonance Imaging: Comparison with Positron Emission Tomography," Circulation Vol. 105, No. 2, 2002, pp. 162-167. doi: $10.1161 / \mathrm{hc} 0202.102123$

[3] R. E. Anderson, "How Many Deaths are Due to Medical Errors?” Jama, Vol. 284, No. 17, 2000, pp. 2188-2189.

[4] D. Antoniucci, R. Valenti, A. Migliorini, G. Moschi, G. Parodi, E. V. Dovellini, L. Bolognese and G. M. Santoro, "Comparison of Impact of Emergency Percutaneous Revascularization on Outcome of Patients $>$ or $=75$ to Those $<75$ Years of Age with Acute Myocardial Infarction Complicated by Cardiogenic Shock," American Journal of Cardiology, Vol. 91, 2003, pp. 1458-1461. doi:10.1016/S0002-9149(03)00397-7
[5] L. Bolognese, N. Carrabba, G. Parodi, G. M. Santoro, P. Buonamici, G. Cerisano and D. Antoniucci, "Impact of microvascular dysfunction on left ventricular remodeling and long-term clinical outcome after primary coronary angioplasty for acute myocardial infarction," Circulation Vol. 109, No. 9, 2004, pp. 1121-1126. doi:10.1161/01.CIR.0000118496.44135.A7

[6] L. Bolognese, N. Carrabba, G. M. Santoro, R. Valenti, P. Buonamici and D. Antoniucci, "Angiographic Findings, Time Course of Regional and Global Left Ventricular Function, and Clinical Outcome in Diabetic Patients with Acute Myocardial Infarction Treated with Primary Percutaneous Transluminal Coronary Angioplasty," American Journal of Cardiology, Vol. 91, No. 5, 2003, pp. 544-549. doi:10.1016/S0002-9149(02)03302-7

[7] V. Caraballo, "Fatal Myocardial Infarction Resulting from Coronary Artery Septic Embolism after Abortion: Unusual Cause and Complication of Endocarditis," Annals of Emergency Medicine, Vol. 29, No. 1, 1997, pp. 175-177. doi:10.1016/S0196-0644(97)70325-1

[8] R. G. Charles, E. J. Epstein, S. Holt and N. Coulshed, "Coronary Embolism in Valvular Heart Disease," Quarterly Journal of Medicine, Vol. 51, No. 202, 1982, pp. 147-161.

[9] E. Donal, D. Coisne, Y. Valy, J. Allal, L. Christaens and R. Barraine, "Myocardial Infarction Caused by Septic Embolism during Mitral Endocarditis," Archives des maladies du coeur et des vaisseaux, Vol. 92, No. 2, 1999, pp. 253-257.

[10] N. Noto, T. Osaka, O. Yamanaka, S. Kobayashi, H. Ozaki and T. Kanoh, "A Case of Acute Myocardial Infarction Due to Coronary Embolism from Left Atrial Thrombus with Atrial Fibrillation," Kokyu To Junkan, Vol. 38, No. 5, 1990, pp. 483-487, in Japanese.

[11] E. G. Quinn and D. J. Fergusson, "Coronary Embolism Following Aortic and Mitral Valve Replacement: Successful Management with Abciximab and Urokinase," Catheterization and cardiovascular diagnosis, Vol. 43, No. 4, 1998, pp. 457-459. doi:10.1002/(SICI)1097-0304(199804)43:4<457::AID-C CD24>3.0.CO;2-F

[12] T. Takenaka, M. Horimoto, K. Igarashi, H. Yoshie, I. Tsujino and M. Morihira, "Multiple Coronary Thromboemboli Complicating Valvular Heart Disease and Atrial Fibrillation," American Heart Journal, Vol. 131, No. 1, 1996, pp. 194-196. doi:10.1016/S0002-8703(96)90070-8

[13] C. Yutani, M. Imakita, H. Ueda-Ishibashi, M. Katsuragi and H. Fujita, "Coronary Artery Embolism with Special Reference to Invasive Procedures as the Source," Modern Pathology, Vol. 5, No. 3, 1992, pp. 244-249.

[14] R. Erbel, "Spontaneous and Interventional Coronary Microembolisation," Heart, Vol. 89, No. 8, 2003, pp. 986-989. doi:10.1136/heart.89.9.986

[15] B. F. Mandell, "Cardiovascular Involvement in Systemic Lupus Erythematosus," Semin Arthritis Rheum, Vol. 17, No. 2, 1987, pp. 126-141. 
[16] M. A. Westwood, F. Shah, L. J. Anderson, J. W. Strange, M. A. Tanner, A. M. Maceira, J. Howard, J. B. Porter, J. M. Walker, et al., "Myocardial tissue characterization and the role of chronic anemia in sickle cell cardiomyopathy," Journal of Magnetic Resonance Imaging, Vol. 26, 2007, pp. 564-568. doi:10.1002/jmri.21018

[17] J. L. Anderson, C. D. Adams, E. M. Antman, C. R. Bridges, R. M. Califf, D. E. Casey, Jr., W. E. Chavey, 2nd, F. M. Fesmire, J. S. Hochman, et al., "ACC/AHA 2007 Guidelines for the Management of Patients with Unstable Angina/Non-ST-Elevation Myocardial Infarction: A Report of the American College of Cardiology/American Heart Association Task Force on Practice Guidelines (Writing Committee to Revise the 2002 Guidelines for the Management of Patients With Unstable Angina/ Non-ST-Elevation Myocardial Infarction) Developed in Collaboration with the American College of Emergency Physicians, the Society for Cardiovascular Angiography and Interventions, and the Society of Thoracic Surgeons endorsed by the American Association of Cardiovascular and Pulmonary Rehabilitation and the Society for Academic Emergency Medicine," Journal of the American College of Cardiology, Vol. 50, 2007, pp. e1-e157.

[18] R. Hardoff, A. Shefer, S. Gips, A. Merdler, M. Y. Flugelman, D. A. Halon and B. S. Lewis, "Predicting Late Restenosis after Coronary Angioplasty by Very Early (12 to $24 \mathrm{~h}$ ) Thallium-201 Scintigraphy: Implications with Regard to Mechanisms of Late Coronary Restenosis," Journal of the American College of Cardiology, Vol. 15, No. 7, 1990, pp. 1486-1492. doi:10.1016/0735-1097(90)92815-J

[19] A. Jain, J. J. Mahmarian, S. Borges-Neto, D. L. Johnston, W. R. Cashion, J. M. Lewis, A. E. Raizner and M. S. Verani, "Clinical Significance of Perfusion Defects by Thallium-201 Single Photon Emission Tomography Following Oral Dipyridamole Early After Coronary Angioplasty," Journal of the American College of Cardiology, Vol. 11, No. 5, 1988, pp. 970-976.

[20] W. Wijns, P. W. Serruys, J. H. Reiber, P. J. de Feyter, M. van den Brand, M. L. Simoons and P. G. Hugenholtz, "Early Detection of Restenosis after Successful Percutaneous Transluminal Coronary Angioplasty by ExerciseRedistribution Thallium Scintigraphy," American Journal of Cardiology, Vol. 55, No. 4, 1985, pp. 357-361. doi:10.1016/0002-9149(85)90375-3

[21] W. W. Wijns and P. W. Serruys, "Coronary Angioplasty in Myocardial Infarction," American Journal of Cardiology, Vol. 56, 1985, p. 1004. doi:10.1016/0002-9149(85)90430-8

[22] R. Bachmann, U. Sechtem, E. Voth, J. Schroder, H. W. Hopp and H. Schicha, "Dipyridamole Scintigraphy and Intravascular Ultrasound after Successful Coronary Intervention," Journal of Nuclear Medicine, Vol. 38, No. 4, 1997, pp. 553-558.

[23] D. R. Holmes, Jr., "Very Early Prediction of Restenosis after Successful Coronary Angioplasty: How Early is Early and can We Identify it?" Journal of American College Cardiology, Vol. 15, No. 2, 1990, pp. 265-266.
[24] J. Rodes-Cabau, J. Candell-Riera, E. Domingo, J. CastellConesa, I. Anivarro, J. Angel, S. Aguade-Bruix, F. Padilla, A. Soto and J. Soler-Soler, "Frequency and Clinical Significance of Myocardial Ischemia Detected Early after Coronary Stent Implantation," Journal Nuclear Medicine, Vol. 42, No. 12, 2001, pp. 1768-1772.

[25] R. Jaffe, S. B. Haim, B. Karkabi, A. Front, S. Gips, G. Weisz, N. Khader, A. Merdler, M. Y. Flugelman, et al., "Myocardial Perfusion Abnormalities Early (12-24 h) after Coronary Stenting or Balloon Angioplasty: Implications Regarding Pathophysiology and Late Clinical Outcome," Cardiology, Vol. 98, No. 1-2, 2002, pp. 60-66. doi: $10.1159 / 000064680$

[26] H. Nagaoka, T. Iizuka, S. Kubota, M. Inoue, E. Yamaguchi, T. Suzuki and R. Nagai, "Redistribution in Thallium-201 Myocardial Imaging Soon after Successful Coronary Stenting-Tomographic Evaluation during Coronary Hyperemia Induced by Adenosine," Japanese Circulation Journal, Vol. 62, No. 3, 1998, pp. 160-166. doi: $10.1253 /$ ici. 62.160

[27] A. Skyschally, R. Schulz, R. Erbel and G. Heusch, "Reduced Coronary and Inotropic Reserves with Coronary Microembolization," American Journal of Physiology - Heart and Circulatory Physiology, Vol. 282, No. 2, 2002, pp. H611-614.

[28] I. Porto, J. B. Selvanayagam, W. J. Van Gaal, F. Prati, A. Cheng, K. Channon, S. Neubauer and A. P. Banning, "Plaque Volume and Occurrence and Location of Periprocedural Myocardial Necrosis after Percutaneous Coronary Intervention: Insights from Delayed-Enhancement Magnetic Resonance Imaging, Thrombolysis in Myocardial Infarction Myocardial Perfusion Grade Analysis, and Intravascular Ultrasound," Circulation, Vol. 114, No. 7, 2006, pp. 662-669. doi:10.1161/CIRCULATIONAHA.105.593210

[29] E. Falk, "Unstable Angina with Fatal Outcome: Dynamic Coronary Thrombosis Leading to Infarction and/or Sudden Death. Autopsy Evidence of Recurrent Mural Thrombosis with Peripheral Embolization Culminating in Total Vascular Occlusion," Circulation, Vol. 71, No. 4, 1985, pp. 699-708.

[30] J. B. Selvanayagam, A. S. Cheng, M. Jerosch-Herold, K. Rahimi, I. Porto, W. van Gaal, K. M. Channon, S. Neubauer and A. P. Banning, "Effect of Distal Embolization on Myocardial Perfusion Reserve after Percutaneous Coronary Intervention: A Quantitative Magnetic Resonance Perfusion Study," Circulation, Vol. 116, No. 13, 2007, pp. 1458-1464. doi:10.1161/CIRCULATIONAHA.106.671909

[31] M. J. Davies and A. C. Thomas, "Plaque Fissuring-The Cause of Acute Myocardial Infarction, Sudden Ischaemic Death, and Crescendo Angina," British Heart Journal, Vol. 53, No. 4, 1985, pp. 363-373. doi:10.1136/hrt.53.4.363

[32] M. J. Davies, A. C. Thomas, P. A. Knapman and J. R. Hangartner, "Intramyocardial Platelet Aggregation in Patients with Unstable Angina Suffering Sudden 
Ischemic Cardiac Death," Circulation Vol. 73, 1986, pp. 418-427.

[33] A. Skyschally, K. Leineweber, P. Gres, M. Haude, R. Erbel and G. Heusch, "Coronary Microembolization," Basic Research in Cardiology Vol. 101, No. 5, 2006, pp. 373-382. doi:10.1007/s00395-006-0616-1

[34] R. Erbel and G. Heusch, "Coronary Microembolization," Journal of the American College of Cardiology, Vol. 36, No. 1, 2000, pp. 22-24. doi:10.1016/S0735-1097(00)00708-7

[35] M. J. Davies, J. M. Bland, J. R. Hangartner, A. Angelini and A. C. Thomas, "Factors Influencing the Presence or Absence of Acute Coronary Artery Thrombi in Sudden Ischaemic Death," European Heart Journal, Vol. 10, No. 3, 1989, pp. 203-208.

[36] M. J. Davies and A. Thomas, "Thrombosis and Acute Coronary-Artery Lesions in Sudden Cardiac Ischemic Death," New England Journal of Medicine, Vol. 310, 1984, pp. 1137-1140. doi:10.1056/NEJM198405033101801

[37] A. Farb, A. L. Tang, A. P. Burke, L. Sessums, Y. Liang and R. Virmani, "Sudden Coronary Death. Frequency of Active Coronary Lesions, Inactive Coronary Lesions, and Myocardial Infarction," Circulation, Vol. 92, 1995, pp. 1701-1709.

[38] I. H. Leach, J. W. Blundell, J. M. Rowley and D. R. Turner, "Acute Ischaemic Lesions in Death Due to Ischaemic Heart Disease. An Autopsy Study of 333 Cases of Out-of-Hospital Death," European Heart Journal, Vol. 16, No. 9,1995, pp. 1181-1185.

[39] M. Michalodimitrakis, A. Mavroforou and A. D. Giannoukas, "Lessons Learnt from the Autopsies of 445 Cases of Sudden Cardiac Death in Adults," Coronary Artery Disease, Vol. 16, No. 6, 2005, pp. 385-389.

[40] D. D. Reichenbach, N. S. Moss and E. Meyer, "Pathology of the Heart in Sudden Cardiac Death," American Journal of Cardiology, Vol. 39, No. 6, 1977, pp. 865-872.

[41] A. Schubert, "Remarks to Statement from the Rate of Cause of Death Due to Ischaemic Heart Diseases," Gesundheitswesen, Vol. 63, No. 12, 2001, pp. 769-774.

[42] P. T. Sexton, K. Jamrozik and J. Walsh, "Sudden Unexpected Cardiac Death among Tasmanian Men," Medical Journal of Australia, Vol. 159, No. 7, 1993, pp. 467-470.

[43] A. Okamura, H. Ito, K. Iwakura, S. Kawano, K. Inoue, Y. Maekawa, T. Ogihara and K. Fujii, "Detection of Embolic Particles with the Doppler Guide Wire during Coronary Intervention in Patients with Acute Myocardial Infarction: Efficacy of Distal Protection Device," Journal of the American College of Cardiology, Vol. 45, No. 2, 2005, pp. 212-215. doi:10.1016/j.jacc.2004.09.062

[44] R. S. Saber, W. D. Edwards, K. R. Bailey, T. W. McGovern, R. S. Schwartz and D. R. Holmes, Jr., "Coronary embolization after balloon angioplasty or thrombolytic therapy: an autopsy study of 32 cases," Journal of the American College of Cardiology Vol. 22,
1993, pp. 1283-1288.

[45] D. Bose, C. von Birgelen, X. Y. Zhou, A. Schmermund, S. Philipp, S. Sack, T. Konorza, S. Mohlenkamp, K. Leineweber, et al., "Impact of Atherosclerotic Plaque Composition on Coronary Microembolization during Percutaneous Coronary Interventions," Basic Research Cardiology, Vol. 103, No. 6, 2008, pp. 587-597. doi:10.1007/s00395-008-0745-9

[46] A. Angelini, P. Rubartelli, F. Mistrorigo, M. Della Barbera, F. Abbadessa, M. Vischi, G. Thiene and S. Chierchia, "Distal Protection with a Filter Device during Coronary Stenting in Patients with Stable and Unstable Angina," Circulation, Vol. 110, No. 6, 2004, pp. 515-521.

[47] G. Heusch, R. Schulz, M. Haude and R. Erbel, "Coronary Microembolization," Journal of Molecular and Cellular Cardiology, Vol. 37, 2004, pp. 23-31. doi:10.1016/j.yjmcc.2004.04.011

[48] R. Erbel and G. Heusch, "Spontaneous and Iatrogenic Microembolization. A New Concept for the Pathogenesis of Coronary Artery Disease," Herz, Vol. 24, No. 7, 1999, pp. 493-495. doi:10.1007/BF03044219

[49] R. Erbel and G. Heusch, "Coronary microembolizationIts Role in Acute Coronary Syndromes and Interventions," Herz, Vol. 24, No. 7, 1999, pp. 558-575. doi:10.1007/BF03044228

[50] E. J. Topol and J. S. Yadav, "Recognition of the Importance of Embolization in Atherosclerotic Vascular Disease," Circulation, Vol. 101, No. 5, 2000, pp. 570-580.

[51] A. Skyschally, M. Haude, H. Dorge, M. Thielmann, A. Duschin, A. van de Sand, I. Konietzka, A. Buchert, S. Aker, et al., "Glucocorticoid Treatment Prevents Progressive Myocardial Dysfunction Resulting from Experimental Coronary Microembolization," Circulation, Vol. 109, No. 19, 2004, pp. 2337-2342. doi:10.1161/01.CIR.0000127961.66744.F4

[52] M. A. Pfeffer, J. M. Pfeffer, M. C. Fishbein, P. J. Fletcher, J. Spadaro, R. A. Kloner and E. Braunwald, "Myocardial Infarct Size and Ventricular Function in Rats," Circulation Research, Vol. 44, No. 4, 1979, pp. 503-512.

[53] H. Dorge, T. Neumann, M. Behrends, A. Skyschally, R. Schulz, C. Kasper, R. Erbel and G. Heusch, "PerfusionContraction Mismatch with Coronary Microvascular Obstruction: Role of Inflammation," American Journal of Physiology - Heart and Circulatory Physiology, Vol. 279, No. 6, 2000, pp. 2587-2592.

[54] R. S. Schwartz, A. Burke, A. Farb, D. Kaye, J. R. Lesser, T. D. Henry and R. Virmani, "Microemboli and Microvascular Obstruction in Acute Coronary Thrombosis and Sudden Coronary Death: Relation to Epicardial Plaque Histopathology," Journal of the American College of Cardiology, Vol. 54, No. 23, 2009, pp. 2167-2173.

[55] M. Carlsson, M. Wilson, A. J. Martin and M. Saeed, "Myocardial Microinfarction after Coronary Microembolization in Swine: MR Imaging Characterization," Radiology, Vol. 250, No. 3, 2009, pp. 703-713.

[56] M. Carlsson, A. J. Martin, P. C. Ursell, D. Saloner and M. 
Saeed, "Magnetic Resonance Imaging Quantification Of Left Ventricular Dysfunction Following Coronary Microembolization," Magnetic Resonance in Medicine, Vol. 61, No. 3, 2009, pp. 595-602.

[57] Y. Gu, Y. Bai, J. Wu, L. Hu and B. Gao, "Establishment and Characterization of an Experimental Model of Coronary Thrombotic Microembolism in Rats," American Journal of Pathology, Vol. 177, No. 3, 2010, pp. 11221130. doi:10.2353/ajpath.2010.090889

[58] D. L. Dicks, M. Carlsson, E. Heiberg, A. Martin, D. Saloner, H. Arheden and M. Saeed, "Persistent Decline in Longitudinal and Radial Strain after Coronary Microembolization Detected on Velocity Encoded Phase Contrast Magnetic Resonance Imaging," Journal of Magnetic Resonance Imaging, Vol. 30, No. 1, 2009, pp. 69-76. doi: $10.1002 / \mathrm{jmri} .21773$

[59] M. Carlsson, D. Saloner, A. J. Martin, P. C. Ursell and M. Saeed, "Heterogeneous Microinfarcts Caused by Coronary Microemboli: Evaluation with Multidetector CT and MR Imaging in a Swine Model," Radiology, Vol. 254, No. 3, 2010, pp. 718-728.

[60] M. Carlsson, N. F. Osman, P. C. Ursell, A. J. Martin and M. Saeed, "Quantitative MR Measurements of Regional and Global Left Ventricular Function and Strain after Intramyocardial Transfer of VM202 into Infarcted Swine Myocardium," American Journal of Physiology - Heart and Circulatory Physiology, Vol. 295, No. 2, 2008, pp. 522-532. doi:10.1152/ajpheart.00280.2008

[61] D. Dicks, D. Saloner, A. Martin, P. Ursell, M. Carlsson and M. Saeed, "Cardiovascular Magnetic Resonance Imaging for Percutaneous Transendocardial Delivery and Three Dimensional Left Ventricular Strain Assessment of VEGF Gene Therapy in Occlusive Infarction," International Journal of Cardiology (2009 (in press) PMID: 19346019 ).

[62] A. Jacquier, C. B. Higgins, A. J. Martin, L. Do, D. Saloner and M. Saeed, "Injection of Adeno-Associated Viral Vector Encoding Vascular Endothelial Growth Factor Gene in Infarcted Swine Myocardium: MR Measurements of Left Ventricular Function and Strain," Radiology, Vol. 245, No. 1, 2007, pp. 196-205.

[63] M. Saeed, A. Martin, A. Jacquier, M. Bucknor, D. Saloner, L. Do, P. Ursell, H. Su, Y. W. Kan and C. B. Higgins, "Permanent Coronary Artery Occlusion: Cardiovascular MR Imaging is Platform for Percutaneous Transendocardial Delivery and Assessment of Gene Therapy in Canine Model," Radiology, Vol. 249, No. 2, 2008, pp. 560-571. doi:10.1148/radiol.2491072068

[64] M. Saeed, A. Martin, P. Ursell, L. Do, M. Bucknor, C. B. Higgins and D. Saloner, "MR Assessment of Myocardial Perfusion, Viability, and Function after Intramyocardial Transfer of VM202, a New Plasmid Human Hepatocyte Growth Factor in Ischemic Swine Myocardium," Radiology, Vol. 249, No. 1, 2008, pp. 107-118.

[65] M. Saeed, D. Saloner, A. Martin, L. Do, O. Weber, P. C. Ursell, A. Jacquier, R. Lee and C. B. Higgins, "AdenoAssociated Viral Vector-Encoding Vascular Endothelial
Growth Factor Gene: Effect on Cardiovascular MR Perfusion and Infarct Resorption Measurements in Swine," Radiology, Vol. 243, No. 2, 2007, pp. 451-460.

[66] M. Saeed, O. Weber, R. Lee, L. Do, A. Martin, D. Saloner, P. Ursell, P. Robert, C. Corot and C. B. Higgins, "Discrimination of Myocardial Acute and Chronic (Scar) Infarctions on Delayed Contrast Enhanced Magnetic Resonance Imaging with Intravascular Magnetic Resonance Contrast Media," Journal of the American College of Cardiology, Vol. 48, No. 10, 2006, pp. 19611968. doi:10.1016/j.jacc.2006.03.071

[67] M. Saeed, A. J. Martin, R. J. Lee, O. Weber, D. Revel, D. Saloner and C. B. Higgins, "MR Guidance of Targeted Injections into Border and Core of Scarred Myocardium in Pigs," Radiology, Vol. 240, No. 2, 2006, pp. 419-426.

[68] M. J. Ricciardi, E. Wu, C. J. Davidson, K. M. Choi, F. J. Klocke, R. O. Bonow, R. M. Judd and R. J. Kim, "Visualization of Discrete Microinfarction after Percutaneous Coronary Intervention Associated with Mild Creatine Kinase-MB Elevation," Circulation, Vol. 103, No. 23, 2001, pp. 2780-2783. doi:10.1161/hc2301.092121

[69] J. B. Selvanayagam, I. Porto, K. Channon, S. E. Petersen, J. M. Francis, S. Neubauer and A. P. Banning, "Troponin Elevation after Percutaneous Coronary Intervention Directly Represents The Extent of Irreversible Myocardial Injury: Insights from Cardiovascular Magnetic Resonance Imaging," Circulation, Vol. 111, No. 8, 2005, pp. 1027-1032.

[70] K. Nassenstein, F. Breuckmann, C. Bucher, G. Kaiser, T. Konorza, L. Schafer, I. Konietzka, A. de Greiff, G. Heusch, et al., "How Much Myocardial Damage is Necessary to Enable Detection of Focal Late Gadolinium Enhancement at Cardiac MR Imaging?" Radiology, Vol. 249, No. 3, 2008, pp. 829-835. doi:10.1148/radiol.2493080457

[71] F. Breuckmann, K. Nassenstein, C. Bucher, I. Konietzka, G. Kaiser, T. Konorza, C. Naber, A. Skyschally, P. Gres, et al., "Systematic Analysis of Functional and Structural Changes After Coronary Microembolization: A Cardiac Magnetic Resonance Imaging Study," Journal of the American College of Cardiology, Vol. 2, 2009, pp. 121-130.

[72] M. Saeed, S. Hetts, J. English, L. Do and M. Wilson, "Quantitative and Qualitative Characterization of the Acute Changes in Myocardial Structure and Function after Distal Coronary Microembolization Using MDCT," Academic Radiology, 2011, in press. doi:10.1016/j.acra.2010.11.016

[73] J. B. Selvanayagam, A. Kardos, D. Nicolson, J. Francis, S. E. Petersen, M. Robson, A. Banning and S. Neubauer, "Anteroseptal or Apical Myocardial Infarction: A Controversy Addressed Using Delayed Enhancement Cardiovascular Magnetic Resonance Imaging," Journal of Cardiovascular Magnetic Resonance, Vol. 6, 2004, pp. 653-661. doi:10.1081/JCMR-120038647

[74] J. B. Selvanayagam, S. E. Petersen, J. M. Francis, M. D. 
Robson, A. Kardos, S. Neubauer and D. P. Taggart, "Effects of Off-Pump Versus On-Pump Coronary Surgery on Reversible and Irreversible Myocardial Injury: A Randomized Trial Using Cardiovascular Magnetic Resonance Imaging and Biochemical Markers," Circulation, Vol. 109, No. 3, 2004, pp. 345-350.

doi:10.1161/01.CIR.0000109489.71945.BD

[75] J. W. Choi, C. M. Gibson, S. A. Murphy, C. J. Davidson, R. J. Kim and M. J. Ricciardi, "Myonecrosis Following Stent Placement: Association between Impaired TIMI Myocardial Perfusion Grade and MRI Visualization of Microinfarction," Catheterization and Cardiovascular Interventions, Vol. 61, No. 4, pp. 472-476 2004.

[76] A. C. Lardo, M. A. Cordeiro, C. Silva, L. C. Amado, R. T. George, A. P. Saliaris, K. H. Schuleri, V. R. Fernandes, M. Zviman, et al., "Contrast-Enhanced Multidetector Computed Tomography Viability Imaging after Myocardial Infarction: Characterization of Myocyte Death, Microvascular Obstruction, and Chronic Scar," Circulation, Vol. 113, No. 3, 2006, pp. 394-404. doi:10.1161/CIRCULATIONAHA.105.521450

[77] A. Jacquier, L. Boussel, N. Amabile, J. M. Bartoli, P. Douek, G. Moulin, F. Paganelli, M. Saeed, D. Revel and P. Croisille, "Multidetector Computed Tomography in Reperfused Acute Myocardial Infarction. Assessment of Infarct Size and No-Reflow in Comparison With Cardiac Magnetic Resonance Imaging," Investigative Radiology, Vol. 43, No. 11, 2008, pp. 773-781.

[78] B. L. Gerber, E. Coche, A. Pasquet, E. Ketelslegers, D. Vancraeynest, C. Grandin, B. E. Van Beers and J. L. Vanoverschelde, "Coronary Artery Stenosis: Direct Comparison of Four-Section Multi-Detector Row CT and 3D Navigator MR Imaging for Detection-Initial Results,” Radiology, Vol. 234, No. 1, 2005, pp. 98-108.

[79] B. L. Gerber, B. Belge, G. J. Legros, P. Lim, A. Poncelet, A. Pasquet, G. Gisellu, E. Coche and J. L. Vanoverschelde, "Characterization of Acute and Chronic Myocardial Infarcts by Multidetector Computed Tomography: Comparison with Contrast-Enhanced Magnetic Resonance," Circulation, Vol. 113, No. 6, 2006, pp. 823833. doi:10.1161/CIRCULATIONAHA.104.529511

[80] A. D. Furtado, M. Carlsson, M. Wintermark, K. Ordovas and M. Saeed, "Identification of Residual Ischemia, Infarction, and Microvascular Impairment in Revascularized Myocardial Infarction Using 64-Slice MDCT," Contrast Media Molecular Imaging, Vol. 3, No. 5, 2008, pp. 198-206. doi:10.1002/cmmi.253

[81] R. B. Jennings, C. Steenbergen, Jr. and K. A. Reimer, "Myocardial Ischemia and Reperfusion," Monographs in Pathology, Vol. 37, 1995, pp. 47-80.

[82] R. T. George, M. Jerosch-Herold, C. Silva, K. Kitagawa, D. A. Bluemke, J. A. Lima and A. C. Lardo, "Quantification of Myocardial Perfusion Using Dynamic 64Detector Computed Tomography," Investgative Radiology, Vol. 42, No. 2, 2007, pp. 815-822.

[83] H. Dorge, R. Schulz, S. Belosjorow, H. Post, A. van de Sand, I. Konietzka, S. Frede, T. Hartung, J.
Vinten-Johansen, et al., "Coronary Microembolization: the Role of TNF-Alpha in Contractile Dysfunction," Journal of Molecular and Cellular Cardiology, Vol. 34, No. 1, 2002, pp. 51-62.

[84] M. Canton, A. Skyschally, R. Menabo, K. Boengler, P. Gres, R. Schulz, M. Haude, R. Erbel, F. Di Lisa and G. Heusch, "Oxidative Modification of Tropomyosin and Myocardial Dysfunction Following Coronary Microembolization," European Heart Journal, Vol. 27, 2006, pp. 875-881. doi:10.1093/eurheartj/ehi751

[85] A. Skyschally, P. Gres, S. Hoffmann, M. Haude, R. Erbel, R. Schulz and G. Heusch, "Bidirectional Role of Tumor Necrosis Factor-Alpha in Coronary Microembolization: Progressive Contractile Dysfunction versus Delayed Protection against Infarction," Circulation Research, Vol. 100, No. 1, 2007, pp. 140-146.

[86] S. J. Brener and E. J. Topol, “Troponin, Embolization and Restoration of Microvascular Integrity," European heart journal, Vol. 21, No. 14, 2000, pp. 1117-1119.

[87] J. B. Selvangyagam, K. Rahimi, A. Banning, A. Cheng, T. Pegg, T. Karamitsos, D. Taggart and S. Neubauer, "Prognostic Significance of Post-Procedural Irreversible Myocardial Injury Detected by Cardiovascular Magnetic Resonance Imaging," Journal of Cardiovascular Magnetic Resonance, Vol.10 (Suppl 1), 2008, pp. A1 (abstract). doi:10.1186/1532-429X-10-S1-A1

[88] J. Bogaert, M. Kalantzi, F. E. Rademakers, S. Dymarkowski and S. Janssens, "Determinants and impact of Microvascular Obstruction in Successfully Reperfused ST-Segment Elevation Myocardial Infarction. Assessment by Magnetic Resonance Imaging," European Radiology, Vol. 17, No. 10, 2007, pp. 2572-2580. doi:10.1007/s00330-007-0627-9

[89] J. Kotani, S. Nanto, G. S. Mintz, M. Kitakaze, T. Ohara, T. Morozumi, S. Nagata and M. Hori, "Plaque Gruel of Atheromatous Coronary Lesion May Contribute to the No-Reflow Phenomenon in Patients with Acute Coronary Syndrome," Circulation, Vol. 106, No. 13, 2002, pp. 1672-1677. doi:10.1161/01.CIR.0000030189.27175.4E

[90] F. Prati, T. Pawlowski, R. Gil, A. Labellarte, A. Gziut, E. Caradonna, A. Manzoli, A. Pappalardo, F. Burzotta and A. Boccanelli, "Stenting of Culprit Lesions in Unstable Angina Leads to a Marked Reduction in Plaque Burden: A Major Role of Plaque Embolization? A Serial Intravascular Ultrasound Study," Circulation, Vol. 107, No. 18, 2003, pp. 2320-2325.

[91] R. J. Frink, P. A. Rooney, Jr., J. O. Trowbridge and J. P. Rose, "Coronary Thrombosis and Platelet/Fibrin Microemboli in Death Associated with Acute Myocardial Infarction," British Heart Journal, Vol. 59, No. 2, 1988, pp. 196-200. doi:10.1136/hrt.59.2.196

[92] P. Bahrmann, G. S. Werner, G. Heusch, M. Ferrari, T. C. Poerner, A. Voss and H. R. Figulla, "Detection of Coronary Microembolization by Doppler Ultrasound in 
Patients with Stable Angina Pectoris Undergoing Elective Percutaneous Coronary Interventions," Circulation, Vol. 115, No. 5, 2007, pp. 600-608. doi:10.1161/CIRCULATIONAHA.106.660779

[93] D. Baumgart, F. Liu, M. Haude, G. Gorge, J. Ge and R. Erbel, "Acute Plaque Rupture and Myocardial Stunning in Patient with Normal Coronary Arteriography," Lancet, Vol. 346, No. 8968, 1995, pp. 193-194. doi:10.1016/S0140-6736(95)91257-6

[94] M. Carlino, J. De Gregorio, C. Di Mario, A. Anzuini, F. Airoldi, R. Albiero, C. Briguori, A. Dharmadhikari, I. Sheiban and A. Colombo, "Prevention of Distal Embolization during Saphenous Vein Graft Lesion Angioplasty. Experience with a New Temporary occlusion and Aspiration System," Circulation, Vol. 99, No. 25, 1999, pp. 3221-3223.

[95] E. Grube, U. Gerckens, A. C. Yeung, S. Rowold, N. Kirchhof, J. Sedgewick, J. S. Yadav and S. Stertzer, "Prevention of Distal Embolization during Coronary Angioplasty in Saphenous Vein Grafts and Native Vessels Using Porous Filter Protection," Circulation, Vol. 104, No. 20, 2001, pp. 2436-2441. doi:10.1161/hc4501.099317

[96] U. Limbruno, A. Micheli, M. De Carlo, G. Amoroso, R. Rossini, C. Palagi, V. Di Bello, A. S. Petronio, G. Fontanini and M. Mariani, "Mechanical Prevention of Distal Embolization during Primary Angioplasty: Safety, Feasibility, and Impact on Myocardial Reperfusion," Circulation, Vol. 108, No. 2, 2003, pp. 171-176. doi:10.1161/01.CIR.0000079223.47421.78

[97] M. Murakami, K. Iwasaki, S. Kusachi, K. Hina, M. Hirota, S. Hirohata, S. Kamikawa, M. Sangawa, K. Yamamoto and Y. Shiratori, "Nicorandil reduces the incidence of minor cardiac marker elevation after coronary stenting," International Journal of Cardiology, Vol. 107, No. 1, 2006, pp. 48-53.

[98] "A Clinical Trial Comparing Primary Coronary Angioplasty with Tissue Plasminogen Activator for Acute Myocardial Infarction. The Global Use of Strategies to Open Occluded Coronary Arteries in Acute Coronary Syndromes (GUSTO IIb) Angioplasty Substudy Investigators," New England Journal of Medicine, Vol. 336, No. 23, 1997, pp. 1621-1628. doi:10.1056/NEJM199706053362301

[99] M. Hori, M. Inoue, M. Kitakaze, Y. Koretsune, K. Iwai, J. Tamai, H. Ito, A. Kitabatake, T. Sato and T. Kamada, "Role of Adenosine in Hyperemic Response of Coronary Blood Flow in Microembolization," American Journal of Physiology, Vol. 250, 1986, pp. H509-518.

[100] M. L. Fokkema, P. J. Vlaar, M. Vogelzang, Y. L. Gu, M. A. Kampinga, B. J. de Smet, G. A. Jessurun, R. L. Anthonio, A. F. van den Heuvel, et al., "Effect of High-Dose Intracoronary Adenosine Administration during Primary Percutaneous Coronary Intervention in Acute Myocardial Infarction: A Randomized Controlled Trial," Circulation Cardiovascular Interventions, Vol. 2, No. 4, 2009, pp. 323-329. doi:10.1161/CIRCINTERVENTIONS.109.858977
[101]A. J. Taylor, N. Al-Saadi, H. Abdel-Aty, J. Schulz-Menger, D. R. Messroghli, M. Gross, R. Dietz and M. G. Friedrich, "Elective Percutaneous Coronary Intervention Immediately Impairs Resting Microvascular Perfusion Assessed by Cardiac Magnetic Resonance Imaging," American Heart Journal, Vol. 151, No. 4, 2006, pp. 891.e1-7.

[102] E. Appelbaum and W. J. Manning, "Science to Practice: Can the Combination of Resting First-Pass Myocardial Perfusion and Late Gadolinium-Enhanced Cardiovascular MR Imaging Help Identify Myocardial Infarction Resulting from Coronary Microembolization?" Radiology, Vol. 250, No. 3, 2009, pp. 609-611. doi:10.1148/radiol.2503082001

[103] A. T. Yan, A. J. Shayne, K. A. Brown, S. N. Gupta, C. W. Chan, T. M. Luu, M. F. Di Carli, H. G. Reynolds, W. G. Stevenson and R. Y. Kwong, "Characterization of the Peri-Infarct Zone by Contrast-Enhanced Cardiac Magnetic Resonance Imaging is a Powerful Predictor of Post-Myocardial Infarction Mortality," Circulation, Vol. 114, No. 1, 2006, pp. 32-39. doi:10.1161/CIRCULATIONAHA.106.613414

[104] A. Schmidt, C. F. Azevedo, A. Cheng, S. N. Gupta, D. A. Bluemke, T. K. Foo, G. Gerstenblith, R. G. Weiss, E. Marban, et al., "Infarct Tissue Heterogeneity by Magnetic Resonance Imaging Identifies Enhanced Cardiac Arrhythmia Susceptibility in Patients with Left Ventricular Dys-Function," Circulation, Vol. 115, No. 15, 2007, pp. 2006-2014. doi:10.1161/CIRCULATIONAHA.106.653568

[105] K. H. Schuleri, M. Centola, R. T. George, L. C. Amado, K. S. Evers, K. Kitagawa, A. L. Vavere, R. Evers, J. M. Hare, et al., "Characterization of Peri-Infarct Zone Heterogeneity by Contrast-enhanced Multidetector Computed Tomography: A Comparison with Magnetic Resonance Imaging," Journal of the American College of Cardiology, Vol. 53, No. 18, 2009, pp. 1699-1707. doi:10.1016/j.jacc.2009.01.056

[106] J. M. de Bakker, F. J. van Capelle, M. J. Janse, A. A. Wilde, R. Coronel, A. E. Becker, K. P. Dingemans, N. M. van Hemel and R. N. Hauer, "Reentry as a Cause of Ventricular Tachycardia in Patients with Chronic Ischemic Heart Disease: Electrophysiologic and Anatomic Correlation," Circulation, Vol. 77, No. 3, 1988, pp. 589-606.

[107] G. W. Stone, J. Webb, D. A. Cox, B. R. Brodie, M. Qureshi, A. Kalynych, M. Turco, H. P. Schultheiss, D. Dulas, et al., "Distal Microcirculatory Protection during Percutaneous Coronary Intervention in Acute ST-Segment Elevation Myocardial Infarction: A Randomized Controlled Trial," Journal of the Aemrican Medical Association, Vol. 293, No. 9, 2005, pp. 1063-1072. doi:10.1001/jama.293.9.1063

[108] J. N. Hamburger and P. W. Serruys, "Treatment of Thrombus Containing Lesions in Diseased Native Coronary Arteries and Saphenous Vein Bypass Grafts Using the AngioJet Rapid Thrombectomy System," Herz, Vol. 22, No. 6, 1997, pp. 318-321. 


\section{doi:10.1007/BF03044282}

[109] T. Ischinger, "Thrombectomy with the X-SIZER Catheter System in the Coronary Circulation: Initial Results from a Multi-Center Study," Journal of Invasive Cardiology, Vol. 13, No. 2, 2001, pp. 81-88.

[110] S. Patel and J. Hermiller, "Embolic Protection: the FilterWire EZ Embolic Protection System," Expert Review of Medical Devices, Vol. 5, No. 1, 2008, pp. 19-24. doi:10.1586/17434440.5.1.19

[111] T. Svilaas, P. J. Vlaar, I. C. van der Horst, G. F. Diercks, B. J. de Smet, A. F. van den Heuvel, R. L. Anthonio, G. A. Jessurun, E. S. Tan, et al., "Thrombus Aspiration during Primary Percutaneous Coronary Intervention," New England Journal of Medicine, Vol. 358, No. 6, 2008, pp. 557-567. doi:10.1056/NEJMoa0706416

[112] M. Gick, N. Jander, H. P. Bestehorn, R. P. Kienzle, M. Ferenc, K. Werner, T. Comberg, K. Peitz, D. Zohlnhofer, et al., "Randomized Evaluation of the Effects of Filter-Based Distal Protection on Myocardial Perfusion and Infarct Size after Primary Percutaneous Catheter Intervention in Myocardial Infarction with and without ST-Segment Elevation," Circulation, Vol. 112, No. 10, 2005, pp. 1462-1469. doi:10.1161/CIRCULATIONAHA.105.545178

[113] M. Srinivasan, C. Rihal, D. R. Holmes and A. Prasad, "Adjunctive Thrombectomy and Distal Protection in Primary Percutaneous Coronary Intervention: Impact on Microvascular Perfusion and Outcomes," Circulation, Vol. 119, No. 9, 2009, pp. 1311-1319. doi:10.1161/CIRCULATIONAHA.108.831453

[114] J. D. Haeck, K. T. Koch, L. Bilodeau, R. J. Van der Schaaf, J. P. Henriques, M. M. Vis, J. Baan, Jr., A. C. Van der Wal, J. J. Piek, et al., "Randomized Comparison of Primary Percutaneous Coronary Intervention with Combined Proximal Embolic Protection and Thrombus Aspiration versus Primary Percutaneous Coronary
Intervention Alone in ST-Segment Elevation Myocardial Infarction: the PREPARE (Proximal Embolic Protection in Acute myocardial infarction and Resolution of ST-Elevation) Study," JACC Cardiovascular Interventions, Vol. 2, No. 10, 2009, pp. 934-943. doi:10.1016/j.jcin.2009.07.013

[115] C. M. Gibson, D. J. Cohen, E. A. Cohen, H. K. Lui, S. A. Murphy, S. J. Marble, M. Kitt, T. Lorenz and J. E. Tcheng, "Effect of Eptifibatide on Coronary Flow Reserve Following Coronary Stent Implantation (an ESPRIT Substudy). Enhanced Suppression of the Platelet IIb/IIIa Receptor with Integrilin Therapy," Am J Cardiol, Vol. 87, No. 11, 2001, pp. 1293-1295. doi:10.1016/S0002-9149(01)01524-7

[116] H. Kunichika, O. Ben-Yehuda, S. Lafitte, N. Kunichika, B. Peters and A. N. DeMaria, "Effects of Glycoprotein IIb/IIIa Inhibition on Microvascular Flow after Coronary Reperfusion. A Quantitative Myocardial Contrast EchoCardiography Study," Journal of the Americqan College of Cardiology, Vol. 43, No. 2, 2004, pp. 276-283. doi:10.1016/i.jacc.2003.08.040

[117] J. A. de Lemos, C. M. Gibson, E. M. Antman, S. A. Murphy, D. A. Morrow, K. C. Schuhwerk, M. Schweiger, P. Coussement, F. Van de Werf and E. Braunwald, "Abciximab and Early Adjunctive Percutaneous Coronary Intervention are Associated with Improved ST-Segment Resolution after Thrombolysis: Observations from the TIMI 14 Trial," American Heart Journal, Vol. 141, No. 4, 2001, pp. 592-598. doi:10.1067/mhj.2001.113574

[118] Y. J. Yang, J. L. Zhao, S. J. You, Y. J. Wu, Z. C. Jing, W. X. Yang, L. Meng, Y. W. Wang and R. L. Gao, "Different Effects of Tirofiban and Aspirin Plus Clopidogrel on Myocardial No-Reflow in a Mini-Swine Model of Acute Myocardial Infarction and Reperfusion," Heart, Vol. 92, No. 8, 2006, pp. 1131-1137. doi:10.1136/hrt.2005.077164 